\title{
Evaluation of Ecological Safety of Water Resources in Changchun
}

\author{
Ruyue Huang, Peng Chen
}

College of Tourism and Geographical Science,Jilin Normal University,Siping 136000,China

\section{长春市水资源生态安全评价

\author{
黄茹月 ${ }^{1}$, 陈鹏 ${ }^{1}$
} \\ 吉林师范大学旅游与地理科学学院, 四平 136000 , 中国}

\section{Abstract}

As China's population continues to grow and the rate of economic development continues to increase, the environment of water resources has been severely damaged, resulting in a serious shortage of water resources. This has become one of the important factors constraining urban development. Therefore, the research on water resources ecological security evaluation is Today's social research is an important topic. Taking Changchun as the research area, based on the connotation, characteristics and research methods of water resources ecological security, the evaluation index system of ecological security of water resources in Changchun is constructed. The evaluation method will adopt the "pressure state response" framework model (PSR, Pressure State Response) .On the basis of the construction of the evaluation index system of water resources ecological security, the analytic hierarchy process is used. The weight of each index is calculated to provide basis for achieving the goal of ecological security assessment of water resources in this study. The results show that the water resources ecology in Changchun is relatively safe, but it is at a critical point of low safety, and it needs effective governance in the future.

Keywords:water resource; Ecological safety of water resources; Evaluation index system
摘要

随着我国人口不断增长, 经济发展速 度的不断提高, 水资源环境遭到严重破 坏, 从而导致水资源严重短缺, 这已经成 为制约城市发展的重要因素之一, 所以进 行水资源生态安全评价研究是当今社会研 究的重要话题。以长春市为研究区, 从水 资源生态安全的内涵、特点以及研究方法 出发, 构建了长春市水资源生态安全评价 指标体系, 评价方法将采用 “压力-状态响应” 框架模型 (PSR, Pressure State Response), 在构建水资源生态安全评价 指标体系基础上, 利用层次分析法计算各 指标权重, 为实现本研究的目标水资源生 态安全评价提供依据。研究结果发现长春 市水资源生态相对较安全, 但已经处于低 安全的临界点, 需要在以后进行有效的治 理。

关键词: 水资源; 水资源生态安全; 评价 指标体系

\section{1. 引言}

近几年, 生态环境恶化、人口激增、工 农商等行业快速增加, 城市不断扩张, 导 致水资源日益短缺。20世纪 90 年代, 水资 源已经成为战略性资源, 被各国列为 “国 家发展战略” 重要目标。我国经济、社会 的快速发展, 对水资源的需求不断增加, 也存在着水资源短缺现象。水资源安全问 题能否解决, 关系到国民、社会, 乃至国 家繁荣兴旺, 因此, 水资源生态安全必须 
引起我们高度重视。水资源生态安全是强 调满足社会经济发展对水资源的需求, 同 时需要满足社会经济可持续发展这一长远 目标。为了实现该目标, 需构建水资源生 态安全体系, 建立可靠的供给水保障体系 和机制, 有效的保护水环境, 治理水灾, 确保各种水工程安全。本文水资源生态安 全评价的研究可为长春市的生态环境和社 会经济的可持续发展提供科学依据。

\section{1 国内外研究现状}

\section{1 国外研究现状}

据 2006 年 3 月 22 日在墨西哥城第四届 世界水资源论坛上对外公布的《世界水资 源开发报告》: 全球用水量在 20 世纪增加 了 6 倍, 增长速度是人口增速的 2 倍, 有 11 人缺水, 26 亿人无法保证用水卫生; 大 部分地区的水质正在下降, 这些地区的淡 水物种和生态系统的多样性正在迅速衰 退, 其退化速度往往快于陆地和海洋系 统; $90 \%$ 的自然灾害与水有关; 到 2030 年 全球粮食需求将提高 $55 \%$, 将需要更多的灌 溉用水, 而这部分用水已经占到全球人类 淡水消耗的近 70\%, 水资源安全问题日趋恶 化。国际社会十分重视水资源安全问题的 研究, 特别是 20 世纪 90 年代以后, 国际 有关组织实施了一系列国际水科学计划, 如国际水文计划、世界气候研究计划、国 际地圈生物圈计划, 全球能量与水分循环 21 世纪研究计划等, 目的是从全球、区域 和流域不同尺度和交叉学科途径, 探讨环 境变化下的水资源安全问题。

国外主要通过评价水资源压力来评价水 资源生态安全方面的问题。英国苏格兰资 源利用研究所应用系统动力学理论, 建立 了提高人口承载能力备选方案模, ECCO

( Enhancement of Carrying Capacity Options) 模型。该模型在 “一切都是能 量” 的假设前提下, 模拟不同发展策略 下, 人口与资源环境承载力之间的弹性关 系, 从而确定了以长远发展为目标的区域 发展优选方案。目前在国际上通用的衡量 水资源压力的宏观单指标中, 最具代表性 的有两个: 一是区域人均水资源量; 二是
水资源开发利用程度。除了上述两个单指 标外, 国外水资源生态安全评价领域常用 的指标还有水贫困指数 (WPI) ${ }^{[1-2]}$ 。国外在 水资源安全方面还有其他方面许多的研 究, 主要集中在水循环、水文情势控制、 水污染、生态环境需水和干旱缺水等方 面。其中以水功能为基准的研究方法有很 多, 通用的研究方法主要有: 传统的流量 计算方法 (又称标准流量法) ; 基于水力 学基础的水力学法; 基于生物学基础的栖 息地法; 基于水污染控制的污染预算法 等。

\section{2 国内研究现状}

国内对水资源生态安全领域的研究起步 于本世纪初, 在建立指标体系时, 大多数 学者主要采用分类指标进行分析, 将水资 源生态安全分为多个子安全系统, 如经济 安全、生态安全、饮水安全等, 少数学者 从水资源总体出发选择指标, 建立指标体 系。也有少数学者从总体上选取指标进行 水资源生态安全的评价。吴国庆 (2001) 在 研究区域农业可持续发展的生态安全时, 从资源生态环境压力、资源生态环境质量 和整治建设能力 3 个方面建立 3 层指标体 系, 利用各指标与 “不安全标准值” 的比 较来建模, 最后综合得出区域的 “生态不 安全度”。国内对水资源安全的研究大致 可分为 3 个阶段: (1)20 世纪 80 年代以前主 要是探讨河道枯、洪流量, 涉及环境用水 问题。

(2)20 世纪 80 年代到 20 世纪 90 年代, 在进行水量的研究同时, 针对水污染日益 严重问题, 国务院也提出了《关于防治水 污染技术政策的规定》, 对水污染的防治 研究提出了技术路线, 但主要集中在宏观 战略方面的研究。

(3) 20 世纪 90 年代以来, 1998 年大洪 水等一系列问题, 国家提出了治水新思路 是对于区域水资源安全的评价, 韩宁平等 构建了一个既有定量目标又有定性目标的 结构性与非结构性相结合的多层次指标体 系, 采用半结构性决策方法进行整体评价 ${ }^{[3-}$ 4]。 
通过了解国内外对水资源生态安全评价 的研究现状, 可以发现目前国际上对水资 源生态安全评价主要通过评价水资源压 力, 而国内学者大部分采用分类指标进行 分析, 只有少数学者通过选择指标建立体 系来研究水资源生态安全问题。本研究也 采用建立指标体系的方法来研究水资源生 态安全, 但同时采用定性与定量分析相结 合的层次分析法以及 “压力-状态-响应” 框架模型, 构建了评价模型, 从而建立了 安全准则, 通过水资源安全指数等级, 可 以对研究区水资源生态安全进行有效治 理。

\section{2 研究区概况及数据来源}

\section{1 研究区概况}

长春地处中国东北平原腹地松辽平原, 西北与松原市毗邻, 西南和四平市相连, 东南与吉林市相依, 东北同黑龙江省哈尔 滨市接壤, 是东北地区天然地理中心、是 重要节点城市之一。长春位于北纬 $43^{\circ} 05$ ' $45^{\circ} 15$, , 东经 $124^{\circ} 18$ ' $\sim 127^{\circ}$ 05' ; 居北半球中纬度北温带。

截至 2016 年末, 长春市户籍总人口为 753.4 万人。其中, 市区人口 437.8 万人, 3 县 (市) 人口 315.6 万人。长春市多年平 均降水量 $560 \mathrm{~mm}$, 年平均径流深 $68.2 \mathrm{~mm}$, 年平均蒸发量为 $858.6 \mathrm{~mm}$, 超过降雨量 $298.6 \mathrm{~mm}$; 降雨年际变化明显, 60 年代平均 降水量为 $576.3 \mathrm{~mm}, 70$ 年代平均降水为 $553.2 \mathrm{~mm}$ 。 80 年代平均为 $586.1 \mathrm{~mm}$ 降水量最 少的年份平均为 $369.9 \mathrm{~mm}$, 最多的年份平均 为 $667.9 \mathrm{~mm}$ 。年内各月降水量差别也很大, 汛期 6-9 月份降水量占全年降水量的 $77.2 \%$, 七、八月份占全年降水量的 $50.6 \%$; 在市域范围内, 降水在地区分布不均匀, 由东南向西北递减 ${ }^{[5]}$ 。

\section{2 数据来源}

本文是以 GIS 为操作平台, 收集、整理 和规范了城市水资源历史数据, 环境背景 数据和经济社会数据等属性数据, 以及卫 星遥感图、城市基础地理信息图, 城市规 划图, 土地利用图等空间数据。

\section{3 水资源生态安全研究方法}

\section{1 文献综合法}

为了更好的构建水资源生态安全评价指 标体系, 收集与整理了水资源生态安全相 关的文献、数据以及资料, 笁选能够准确 表达水资源生态安全评价各指标, 为构建 水资源生态安全评价指标体系提供依据。

\section{2 层次分析法}

层次分析法是将与决策有关的元素分解 成目标、准则、方案等层次, 在此基础上 进行定性与定量分析的决策方法。该方法 具有系统、简洁与灵活等特点 ${ }^{[6-7]}$ 。

\section{3 德尔菲法}

德尔菲法主要是通过专家小组给出其通 过分析得来的预测行家意见。专家小组经 过组内组外相互多次的协商, 能使得专家 小组给出的由研究得来的预测性意见趋于 集中, 从而专家小组根据分析的发展趋势 得出有效的预测行结论。

\section{4 数学模型}

在对本论文的研究中, 主要采用的数学 模型 “压力-状态一响应” 框架模型, 此模 型能够有效地对水资源生态安全进行精确 地评价。该数学模型主要说明的是随着国 内人口的不断增长、经济社会的快速发 展, 这些不可避免的问题将给水资源以巨 大压力。本研究在构建水资源生态安全评 价指标体系基础上, 利用层次分析法计算 各指标权重, 为实现本研究目标水资源生 态安全评价提供依据。

\section{4 长春市水资源生态安全评价指标体系 构建}

\section{1 构建原则}

本研究的构建原则有科学性原则、实用 性原则、系统性原则、可行性原则和发展 性原则。科学性原则的目的是系统、科学 有效地把水资源生态安全的基本特征淋淋 尽致的展现出来, 每一项指标要科学有效 的反映水资源生态安全的基本特征, 同时 
每一项本身都应有合理的表示范围, 避免 与其它指标之间的关联和含义范围的重叠 [8]。实用性原则要求各指标应具备可测性、 易获取性及统计数据要确保权威性。系统 性原则在构建评价指标体系过程中需要明 确相应的评价层次, 构建层次分明的水资 源生态安全评价指标体系。水资源生态安 全评价指标系统篮选需要满足具有一定的 代表性, 能够明确的表征评价内容。评估 指标体系应确保在实现数量和质量组合的 同时适当考虑数据的可用性和可靠性以及 量化指标的可行性。各指标体系的设计及 评价指标的选择必须以科学性为原则, 各 评价指标应该具有典型代表性, 不能过多 过细, 使指标过于繁琐, 相互重叠, 指标 又不能过少过简, 避免指标信息遗漏, 出 现错误、不真实现象。根据构建原则, 为 指标体系的构建提供依据。

\section{2 指标体系构建}

指标是复杂事件或系统的信号, 是一组 反映系统特性或显示发生何种事情的信 息, 是从数量方面说明一定社会总体现象 的某种属性或特征, 它可以是数量概念, 也可以是具体数值, 既有定性的指标又有 定量的指标, 既有动态的指标又有静态的 指标。笁选出具有代表性的指标, 并按其 特征进行组合, 就构成水资源安全的评价 指标体系, 从而能够从整体上反映区域水 资源安全的基本状况 ${ }^{[9]}$ 。同时按照指标体系 构建原则及考虑实际情况, 从水资源的社 会、经济和生态安全等方面出发, 对长春 市水资源生态安全评价指标进行了篮选, 并构建水资源生态安全评价指标体系（表 1)。

\section{3 评价模型构建}

评价模型采用的是定性与定量分析相结 合的层次分析法, 它是解决复杂系统中多 层次、多结构、单目标安全评价的较好方
表 1 水资源生态安全评价指标体系

\begin{tabular}{|c|c|c|c|c|}
\hline 目标层 & 制约层 & 要素层 & 指标层 & 权重 \\
\hline \multirow{22}{*}{$\begin{array}{l}\text { 水 } \\
\text { 资 } \\
\text { 源 } \\
\text { 生 } \\
\text { 态 } \\
\text { 安 } \\
\text { 全 } \\
\text { 评 } \\
\text { 价 } \\
\text { 指 } \\
\text { 标 } \\
\text { 体 } \\
\text { 系 }\end{array}$} & \multirow[t]{6}{*}{ 压力 } & \multirow[t]{2}{*}{$\begin{array}{l}\text { 人口压 } \\
\text { 力 }\end{array}$} & 人口密度 & 0.029508 \\
\hline & & & $\begin{array}{l}\text { 人口自然 } \\
\text { 增长率 }\end{array}$ & 0.032734 \\
\hline & & \multirow{2}{*}{$\begin{array}{l}\text { 社会发 } \\
\text { 展压力 }\end{array}$} & 人均 GDP & 0.044596 \\
\hline & & & 城市化率 & 0.050097 \\
\hline & & \multirow[t]{2}{*}{$\begin{array}{l}\text { 水资源 } \\
\text { 压力 }\end{array}$} & $\begin{array}{l}\text { 年总降水 } \\
\text { 量 }\end{array}$ & 0.037585 \\
\hline & & & $\begin{array}{l}\text { 人均资源 } \\
\text { 占有量 }\end{array}$ & 0.029462 \\
\hline & \multirow[t]{9}{*}{ 状态 } & \multirow[t]{2}{*}{$\begin{array}{l}\text { 水资源 } \\
\text { 利用率 }\end{array}$} & $\begin{array}{l}\text { 地下水利 } \\
\text { 用率 }\end{array}$ & 0.061416 \\
\hline & & & $\begin{array}{l}\text { 河湖水利 } \\
\text { 用率 }\end{array}$ & 0.032809 \\
\hline & & \multirow[t]{3}{*}{ 水质 } & $\begin{array}{l}\text { 饮用水利 } \\
\text { 用率 }\end{array}$ & 0.063033 \\
\hline & & & $\begin{array}{l}\text { 工业废水 } \\
\text { 排放达标 } \\
\text { 率 }\end{array}$ & 0.053069 \\
\hline & & & $\begin{array}{l}\text { 河流污染 } \\
\text { 强度 }\end{array}$ & 0.033460 \\
\hline & & \multirow{4}{*}{$\begin{array}{l}\text { 水环境 } \\
\text { 状况 }\end{array}$} & 河流断流 & 0.078264 \\
\hline & & & $\begin{array}{l}\text { 区域内坡 } \\
\text { 度率大于 }\end{array}$ & \\
\hline & & & 等于 25 & 0.049799 \\
\hline & & & $\begin{array}{l}\text { 森林覆盖 } \\
\text { 率 }\end{array}$ & 0.078264 \\
\hline & \multirow[t]{7}{*}{$\begin{array}{l}\text { 建设能 } \\
\text { 力 }\end{array}$} & \multirow[t]{3}{*}{$\begin{array}{l}\text { 状态改 } \\
\text { 善指标 }\end{array}$} & $\begin{array}{l}\text { 城市污水 } \\
\text { 处理率 }\end{array}$ & 0.040700 \\
\hline & & & $\begin{array}{l}\text { 水土流失 } \\
\text { 治理率 }\end{array}$ & 0.062286 \\
\hline & & & $\begin{array}{l}\text { 城市人均 } \\
\text { 绿地 }\end{array}$ & 0.035674 \\
\hline & & \multirow[t]{4}{*}{$\begin{array}{l}\text { 可持续 } \\
\text { 性指标 }\end{array}$} & $\begin{array}{l}\text { 环保投资 } \\
\text { 占 GDP 比 } \\
\text { 重 }\end{array}$ & 0.056176 \\
\hline & & & $\begin{array}{l}\text { 每万人中 } \\
\text { 科技人员 } \\
\text { 所占比重 }\end{array}$ & 0.050720 \\
\hline & & & $\begin{array}{l}\text { 退耕还林 } \\
\text { 面积 }\end{array}$ & 0.044932 \\
\hline & & & $\begin{array}{l}\text { 新能源使 } \\
\text { 用率 }\end{array}$ & 0.035401 \\
\hline
\end{tabular}

法 ${ }^{[10-11]}$ 。同时采用 “压力-状态-响应” 框架 模型, 在构建水资源生态安全评价指标体 系基础上, 利用层次分析法计算各指标权 重, 各指标安全指数计算过程如下, 从而 构建了评价模型:

已知 $x_{i j}$ 为第 $j$ 年的第 $i$ 项指标, 设 $P$ $\left(x_{i j}\right)$ 为 $x_{i j}$ 的指标安全指数, 且 $0 \leq P\left(x_{i j}\right) \leq 1$, 又知 $X S_{i}$ 为第 $i$ 项指标 的阈值, 则 $x_{i j}$ 的指标安全指数 $P\left(x_{i j}\right)$ 确 定方法如下:

(1) 对于效益型指标 当 $x_{i j}>0$ 且 $X S_{i}>0$ 时 


$$
\begin{gathered}
P\left(x_{i j}\right)=\left\{\begin{array}{c}
1, x_{i j} \geq X S_{i} \\
\frac{x_{i j}}{X S_{i}}, x_{i j}<X S_{i}
\end{array}\right. \text { (1) } \\
\text { 当 } x_{i j}<0 \text { 且 } X S_{i}<0 \text { 时 } \\
P\left(x_{i j}\right)=\left\{\begin{array}{c}
1,\left|x_{i j}\right| \leq\left|X S_{i}\right| \\
\frac{x_{i j}}{X S_{i}},\left|x_{i j}\right|>\left|X S_{i}\right|
\end{array}(2)\right. \\
\text { 当 } X S_{i}<0<x_{i j} \text { 时 } P\left(x_{i j}\right)=1 \quad(3) \\
\text { 当 } x_{i j}<0<X S_{i} \text { 时 } P\left(x_{i j}\right)=0 \text { (4) }
\end{gathered}
$$

(2) 对于成本型指标

当 $x_{i j}>0$ 且 $X S_{i}>0$ 时

$$
P\left(x_{i j}\right)=\left\{\begin{array}{c}
1, x_{i j} \leq X S_{i} \\
\frac{X S_{i j}}{x_{i j}}, x_{i j}>X S_{i}
\end{array}\right.
$$

当 $x_{i j}<0$ 且 $X S_{i}<0$ 时

$$
P\left(x_{i j}\right)=\left\{\begin{array}{c}
1,\left|x_{i j}\right| \geq\left|X S_{i}\right| \\
\frac{X S_{i j}}{x_{i j}},\left|x_{i j}\right|<\left|X S_{i}\right|
\end{array}\right.
$$

当 $x_{i j}<0<X S_{i}$ 时 $P\left(x_{i j}\right)=1$ (7)

当 $X S_{i}<0<x_{i j}$ 时 $P\left(x_{i j}\right)=0$ (8)

生态安全指数模型:

按照上述公式 (1) - (8) 给出计算公 式, 通过对各指标安全指数计算, 可得出 水资源生态安全指数 $P\left(x_{i j}\right)$ 。具体指数模型 如下:

$$
S\left(x_{i j}\right)=w_{i} \cdot P\left(x_{i j}\right)(9)
$$

因此, 要计算第 $j$ 年的水资源生态安全指 数 $S\left(x_{j}\right)$ 模型如下:

$$
S\left(x_{j}\right)=\sum_{i=1}^{n} w_{i} \cdot P\left(x_{i j}\right)(10)
$$

\section{4 安全准则建立}

水资源生态安全指数计算完成后, 需要 对计算结果进行等级划分, 而划分等级的 标准就成为了重点。为了确定水资源生态 安全变化是否在正常范围内, 依据上述模型 计算结果水资源生态安全指数和某一年的 综合生态安全指数, 综合考虑将水资源生 态安全指数划分为四个等级, 见表 2 。

表 2 水资源生态安全指数划分标准

\begin{tabular}{cccc}
\hline 不安全 & 低安全 & 较安全 & 高安全 \\
\hline 低于 0.4 & $0.4-0.6$ & $0.6-0.8$ & 高于 0.8 \\
\hline
\end{tabular}

利用上述指标体系与模型计算出研究区 水资源生态安全指数 (2017 年) 为
0.697334, 说明长春市水资源生态相对较 安全, 但已经处于低安全的临界点, 需要 在以后进行有效的治理。

\section{5 结论与讨论}

\section{1 结论}

水是人类不可缺少的自然资源之一, 亦 是战略性资源与社会资源, 因此, 水资源 安全问题便成为一个国家的重中之重。本 文根据构建原则构建了长春市水资源生态 安全评价指标体系以及评价模型的构建, 实现了长春市水资源生态安全评价研究。 研究表明长春市水资源生态相对较安全, 但是其安全指数较低, 需要进行有效治 理, 防止出现生态环境恶化等问题。

\section{2 讨论}

由于论文研究的时间有限, 加上研究区 一些相关重要数据无法获取等实际情况的 限制, 所以对长春市水资源生态安全评价 的研究不够深入。应该利用物联网、云平 台、大数据等技术建立全国水资源安全监 控平台, 实现水资源安全的网络化综合安 全管理, 消除水资源安全的诸多隐患。

\section{致谢}

本研究得到了国家社会科学基金项目 (41501557) 的资助。

\section{参考文献}

[1] 张晓岗,刘昌明, 高媛媛, 王红瑞. 水资源 安全若干问题研究. 中国农村水利水 电,2011(01):9-13.

[2] Sullivan C, Calculating a water poverty index. WorldDevelopment, 2002, 30(7): 1195-1210.

[3] 贾绍凤,张士锋.海河流域水资源安全评 价.地理科学进展,2003,22(04):379-387.

[4] 刘杰,林少华,赵伟丽.水资源安全浅析与 展望.能源与环境,2011(01):19-20.

[5] 张朋飞. 长春市水资源承载力研究. 吉林 大学, 2008 .

[6] 李仰斌,畅明琦.水资源安全评价与预警 研究.中国农村水利水电,2009(01):1-4.

[7] 王莲芬, 许树柏. 层次分析法引论. 北京: 中国人民大学出版社,1990,1-18. 
[8] Chen P, Zhang J Q, Sun Y Y, Liu X J.Wargamemapping and implementation for emergency evacuation of residents in urban waterlogging disaster.Journal of Risk Analysis and Crisis Response,2018,8(1):43-51.

[9] 谢志高, 习树峰,徐建军, 葛萌. 城市水资 源安全评估及保障措施研究. 地下 水,2014,36(04):243-246.

[10] 王远坤,夏自强,曹升乐.水安全综合评价 方法研究.河海大学学报: 自然科学版, 2007, 35(6): 618-621.

[11] 杨博,南昊. 我国水资源现状及其安全对 策研究.太原学院学报 (自然科学 版),2016,34(01):9-12. 